\title{
AN ECOLINGUISTIC ANALYSIS OF LINGUISTIC DISCOURSES IN ADVERTISEMENTS FRAME STORIES TO ENHANCE THEIR IMPORTANCE TO REPLACE NATURAL PRODUCTS
}

Quratul Ain ${ }^{1}$, Fasih Ahmed ${ }^{2 *}$, Muhammad Nawaz ${ }^{3}$

${ }^{1}$ Lecturer Department of English, Women University, Swabi KP, Pakistan; ${ }^{2 * 3}$ Assistant Professor, Department of Humanities, COMSATS, Islamabad, Pakistan.

Email: ${ }^{1}$ quratulainshah12@yahoo.com, ${ }^{2 *}$ fasih.ahmed@ comsats.edu.pk, ${ }^{3}$ muhammad.nawaz@ comsats.edu.pk Article History: Received on $14^{\text {th }}$ February 2021, Revised on $12^{\text {th }}$ March 2021, Published on $20^{\text {th }}$ March 2021

\section{Abstract}

Purpose of the study: The purpose of the research is to analyze the linguistic features of the advertisements, to reveal the stories, developed by manufacturers, which appear to be ecologically protective and aligned with the values of ecosophy. Further, it aims to identify the role of language in establishing ecological preferences for consumers.

Methodology: The data has been collected from the official websites of five food manufacturing companies, which is made limited to beverages and dairy products. The advertisements are analysed under the theoretical framework of Agenda Setting Theory and Framing Theory, using the model of ecolinguistic analysis by Stibbe (2015).

Main Findings: It is incurred that the food manufacturing companies develop different stories that are succinctly insinuated, where the readers consider them mundane but the stories instill certain perceptions in readers' minds and tame the purchase choices of consumers in daily life, through the use of language.

Application of this study: The research dismantles the ecological stance of the discourses and evaluates them in the light of ecosophy, it is helpful for the general public to identify the ecologically destructive discourses and how food manufacturers can improvise their discourses to increase consumerism. The language is used in such an emollient manner that the readers assume it to be for the sake of marketing but they clad the ideology of consumerism in each story.

Novelty/Originality of this study: The study is unique in the sense that it involves the area of linguistics in combination with ecology. It unveils how linguistics discourses in advertisements frame stories to replace the use of natural products. The linguistic discourses are used as a tool for commercial purposes, however, the purpose is to commercially glorify the product as a better source of natural outcome in front of consumers.

Keywords: Ecolinguistics, Commercial Discourses, Language, Story, Ecological Preferences, Metaphors, Identity, Erasure, Conviction.

\section{INTRODUCTION}

In the contemporary world, the success of any company relies on the efficacy of its advertisements. For this purpose, the advertising agencies make use of captivating language to grab consumers' attention and to increase market share (Saeed, Ahmed \& Mukhtar, 2001). During this process, they often propagate such dogmas that may not be in congruence with the prevalent ideologies and principles. Advertisement is a mode of communication, which persuades the masses to decide on the purchase of a product and helps the marketers in triggering economic growth. For this purpose, different modes are used for promotion such as television, commercial radio advertisement, magazines, newspaper, outdoor advertising, blogs, websites, and text messages (Ahmed \& Ashfaq, 2013; Haider \& Shakib, 2018). In advertisements, language plays a vital role in shaping people's behaviour. The advertising agency may seek the help of language and visuals to persuade the audience. During this process, the emotions of the audience are also triggered, which is either the mood while watching the commercial or the cognitive evaluation about the product (Yang, Lee, Kwak, Choi, Kim, \& Kim, 2015).

The discourses about the environment or ecosystem are called environmental discourses which are often present in everyday life including media. Critical ecolinguistic analysis, as a sequel and furtherance of critical linguistic studies, tries to highlight the role played by discourse in sustaining unsustainable consumerism and capitalist fetishism on material growth (Yuniawan, Rokhman, Rustono \& Mardikantoro, 2017). According to Arran Stibbe (2015), "ecolinguistic analyses language to reveal stories we live by, judge those stories according to an ecosophy, and contributes to the search for new stories to live by" (p.183). These stories include ideologies, metaphors, frames, evaluation, identities, conviction, erasure, and salience. The focus of this research is an ecolinguistic analysis of discourses of five food manufacturing companies' dairy and beverages products under the theoretical framework Framing Theory (Ardèvol-Abreu, 2015). As advertisements may vary across different countries, in the case of this study, the commercial advertisements of these products from Pakistan have been selected. The study has focused on the following research questions.

RQ1: What kind of stories are developed by product manufacturers through their advertisements? 
RQ2: How do the product manufacturers set ecological preferences through the use of language?

\section{LITERATURE REVIEW}

A language is a powerful tool that does great work in the world of capitalism. It has the power to control people's minds and behaviour. Therefore, media companies use language as a tool for different marketing strategies to control highly competitive and active markets. According to (Hamid, 2015), in advertisements, the descriptions give us dreams of beauty or a sense of fulfillment, suggestions for banned pleasures and satisfaction; words give us the information we need, the product design, the addresses where we can buy it, through price (p. 135).

The advertising communication procedure is multifaceted and its language has a strong influence on the community and their behaviour. Specific language options are crucial for communicating messages that impact people. It has been noticed that when the "right" advertisement is used it can be very persuasive. It can be powerful in the way that it can alter opinions and make people behave in a certain manner. A strong advertisement can also play with the audience's feelings, fear, confidence, desire, awareness, and self-confidence (Johannessen et al., 2010).

Ecolinguistics is an interdisciplinary field in which language is studied in combination with ecology (Chen, 2016). Conversations among ecolinguists, relating to the description of 'ecology' in this particular circumstance, i.e. the restriction of the objects of study in ecolinguistics, has made it comprehensible, while some authors limit their aim to the awareness and presentation of ecological issues in texts, others operate from a wider viewpoint.

According to Stibbe (2014), ecolinguistics analyzes language to disclose the stories we live by, adjudicates those stories in philosophical terms, upholds stories that oppose the ecological philosophy, and contributes to explore for new stories to live by. The main concern of ecology is a dedication to environmental balance, on the contrary to positivist views, discards the separation among human beings and nature under Cartesian dualism and suggests that environmental crises demand not only technical solutions but also ethical contemplation of anthropocentric activities (Naess \& Drengson, 2008).

The stability between formal language studies and critical linguistics, including critical discourse studies, has become an imperative option for the alliance of subjugated and oppressed people, incorporating the marginalized local languages and utilization of human, educational and natural resources. This is why, critical eco-linguistic as the furtherance of critical linguistic studies, needs to be included in prospective linguistic analysis (Yuniawan, Rokhman, Rustono \& Mardikantoro, 2017). Recent studies of linguistics have influenced interdisciplinary science, viz critical discourse analysis. The amalgam of these two sciences is named critical eco-linguistic. Critical ecology explores the discussion about the ecosystem in different forms of discourses, which concern people and the surrounding environment. The environmental discourse with all its signs (oral text, written text, and images) is called green discourse (Muhlhausler, 2019).

Green advertisements are gaining significance day-to-day due to an increase in awareness of environmental protection. In recent years, corporations have started to go green and promote green practices and green marketing products, as a way to improve the quality of lifestyle to meet customer's needs. Jayakumar \& Kiruthiga (2019) investigated the factors influencing the green purchasing of consumers. The study helps marketers to understand the views of consumers and how they make their green purchase decisions. This research outcome has led to boost the purchase and use of green products in young people. Hartmann, Apaolaza, and Alija (2013) presented a theoretical framework hypothesizing that images of nature offered in the advertisements, develops an impact on cognitive meaning and memory. Three experimental studies were conducted, including an eye-tracking experiment, which successfully tackled side effects, information processing, and acquaintance to nature in advertising and also gave evidence to support published outcomes. The results reinforced the hypothesis that advertisements that contain visual images of pleasing natural sceneries may elicit akin personal responses practiced in a pleasing ecological environment, which is an essential pre-requisite for suggesting cognitive effects. As hypothesized, promotional advertisements containing pleasing nature images achieved higher recall scores compared to identical advertisements showing various other attractive images. Chan (2000) examined how the nature of environmental claims can influence the communication efficacy of green advertisements and how the green image of the source country can modify the relationship of the advertisement type to the effectiveness. Applying $4 \times 2$ factorial research to investigate 800 subjects in Guangzhou, China, the study showed that the claim type of environmental demand and green image of the source country has a major impact on the efficacy. The research showed that the two factors combined to represent an important interactional impact on performance. The findings reiterate marketers about the value of taking a situational perspective, while they are carving their environmental demands.

Considering the literature review studied for the topic of analysis, there is a lack of practical approach in the application of ecolinguistic framework on the discourses that are seemingly mundane but they underpin stories of ecological destruction or protection. The food manufacturing companies elaims claim to give a quality, healthier, and fit lifestyle through a range of their food products. The data selected for analysis is the discourses of five food manufacturing companies to reveal the underlying stories their linguistic features convey and to dismantle their ecological stance through the use of language. 


\section{THEORETICAL FRAMEWORK}

The theoretical framework of the study underpins Agenda Setting Theory and Framing Theory, which are discussed in the following section.

Agenda Setting Theory: The Agenda Setting Theory centers around the fact that there exists a correlation between the events that happen in the world and the images or representation of those events, in the public's mind (McCombs and Shaw, 2016). According to them, "the mass media set the agenda for each political campaign, influencing the salience of attitudes toward the political issues" (p. 177). According to Coleman, McCombs, Shaw, and Weaver (2009), the first-level agenda can be defined as:

"The process of the mass media presenting certain issues frequently and prominently with the result that large segments of the public come to perceive those issues as more important than others . . the more coverage an issue receives, the more important it is to people" (p. 147).

Framing Theory: Framing explains the process of thinking and reflecting on the content of stories and news items in an acquainted context (Arowolo, Sunday, 2017). According to Arowolo, Sunday (2017) the concept of framing catches the attention of the audience to certain objects and some specific attributes of those objects, which are covered in the news. Thus, frames can also be described as a way of structuring ideas and topics, making a link between stories and developing narratives over time and space.

Davie (2011) also made the same remark that the framing theory can be perceived as congruent to second-level agendasetting, which informs the audience how to think about an issue, along with what to think about. The former is covered in framing theory and second-level agenda setting while the latter one is first-level agenda-setting. Nevertheless, McCombs (2005) McCombs, \& Shaw (2016) have defined frames as a special case of attributes, in which not all attributes pertain to frames. McCombs discerns frame as a pronounced feature or attribute of an issue within the message communicated. It covers the main theme, describing the most pronounced and pervasive attribute of an issue or object. In McCombs' words, "attributes defining a central theme are frames" (McCombs, 2016).

\section{RESEARCH DESIGN}

The qualitative approach has been used to carry out the research. The present study has focused on the advertisements of beverages and dairy products, taken from the official websites of five food manufacturing companies during the year 2019. The study selected only five multinational companies that sell their products in many countries. Based on their expertise, their unique method of calling the general public is more sophisticated and appealing as compared to local companies and their commercial advertisement.

\section{RESEARCH MODEL}

The ecolinguistic framework by Stibbe (2015) has been selected to supplement the researchers' argument The aforementioned theories supplement the argument of Stibbe's framework of ecolinguistics that certain stories (mental models or structures) are prevalent around us and we exposed to them without consciously selecting them or becoming aware of the facts that they are mere stories. These stories are imbibed in our daily lives and have become-stories-we-live-by. The storieswe-live-by are present all around us for example in advertisements, news, textbooks, politics, law, medicine, and even in our daily conversations. These stories subsequently affect people's behaviour and the choices they make in their lives. As this study is based on the advertisements of food manufacturing companies, the linguistic choices made by these companies, which can be called their agendas, have constructed certain stories that have an impact on human lives and the nature around us.

Stibbe's framework of ecolinguistics is one of the methods that deal with language ecology. It supports the argument of the current research because it has a concrete approach for analysing the linguistic features to unleash the stories and the ecological stance of a discourse, which is established through language. Stibbe starts with the notion that some stories are prevalent in the society that is not the traditional narratives but mental models, which exist in between the lines of discourses (p. 05). These cognitive structures are problematic because they are pervasive that people in a community do not treat them as stories rather as reality, which he called "stories-we-live-by" (p.06). These stories eventually affect human behaviour. The most dominating story is that of unlimited economic growth in industrial societies. When economic growth is the only objective to strive for, then it promotes the ideology that human beings can exploit nature and its resources for consumerism. Stibbe's framework works to expose and challenge those stories that cause damage to the ecosystem. The same framework also attempts to reveal and promote the stories which are beneficial to the ecosystem. Such beneficial discourses are promoted to produce more discourses of the same kind, to benefit the world around. The eight different forms of stories identified by Stibbe (2015) are ideology, framing, metaphor, evaluation, identity, conviction, erasure, and salience. The present study evaluated only four stories; identity, frame, ideology and evalution. 


\section{SAMPLE}

The data have been collected from the official website of five multinational food manufacturing companies. The data is made limited to beverages and dairy products of the selected companies. There is a total of twenty (20) advertisements, in which four (04) advertisements are taken from each company.

\section{SETTING}

The advertisements selected are of five food manufacturing companies. The advertisements which are analyzed in this study, are those which are produced during the year 2019 and for the Pakistani context.

\section{RESULTS AND DISCUSSION}

\section{Products of Company "A"}

\section{Product 1(A)}

Ideology: According to Stibbe (2015) in 'functionalisation social actors are referred to in terms of activity, in terms of something they do (p. 36). The same example can be seen in company A, where it is claimed that the product "delights consumers". Human beings are reduced to the role of mere consumers, who consume only. It is implicitly promoting the ideology of consumerism under the veil of the promise of providing good and healthy dairy products. The transitive clauses used in the text, reveals that the product has an active role i.e. actor and sensor of the material and mental processes. As in the advertisement, it is stated that the product "has perfected the process", "delights consumers", "provides wholesome nourishment" and "makes you fall in love" clearly illustrates that the role of the product is that of a doer.

Evaluation: The appraisal pattern used in the descriptions makes it a positive evaluation and has assigned all the good qualities to the product. As in the advertisement, words and phrases like "fascinating tastes", "dairy expertise", "perfected", "delights consumers", "signature smooth, rich and creamy taste", "dairy goodness", "wholesome nourishment", "healthy", "good vision", "supports" are used, which are positive lexical items and evaluate the story of the product as a positive evaluation through the explicit use of adjectives.

\section{Product 2(A)}

Ideology: The ideology that is prevalent in the advertisement of powder milk of company A is "purchase of a product is a shortcut to wellbeing" (Stibbe, p. 25). In the advertisement, it is stated that the product "believes that healthy children have a greater chance at succeeding in their academic and extra-curricular pursuits", the product's "mission to strengthen the children by eradicating iron deficiency, for a happier, brighter future." Through entailment, it is claimed that to achieve academic excellence and success, a child needs to drink this milk. For the sake of consumerism, the purchase of this particular product is presented as a key to get success in academics. Also, it claims that it "empowers mothers" which disseminates the ideology of empowerment of mothers through the purchase of the product. Empowerment of mothers is linked with giving children the drink for a better future, although, there are many other natural substitutes or supplements for eradicating iron deficiency, its linkage with mother's empowerment has made it more appealing for the consumers to purchase the product. The ideology embedded in this discourse contradicts ecosophy where human-made artificially processed food items are presented as a substitute for natural ingredients.

Framing: The trigger words, "healthy children", "academic and extra-curricular pursuits", "strengthen the children", "happier, brighter future", "strong foundation" and "better future" are mapped on the target domain of powder milk, which is associated with the source frame of healthy and successful children. The story of the powder milk presents a problem frame i.e. iron deficiency in children, then the solution frame is presented i.e. the product. The product claims to be the solution to iron deficiency and also helps in a happy and brighter future. The relationship developed here is that of entailment, if children will start drinking this milk, iron deficiency will be eradicated. The framing used here is, this product is a solution to iron deficiency.

Evaluation: Positive appraisal items are used for the powder milk that it eradicates iron deficiency through the use of positively connoted words while describing the product. The lexical items "eradicating iron deficiency", "happier", "brighter future", "empower" and "better future" make it a positive evaluation and the consumers start believing in their stories.

Identity: It develops an identity for human beings through consumerism as it "empowers mothers". It is giving an identity to those women, who purchase this product. The purchase of the product gives the identity of empowered women to a particular group of mothers and also to the children who consume this product, they will have a better future i.e. successful people. It is placing the consumers into this specific group by assigning them an identity, through the purchase of this product. 


\section{Product 3(A)}

Identity: The pronouns "you" and "your" are used to reach the readers directly. It places the readers in the subject position, using the product. Whether the readers use the product in real life or not but in the text the subject position is given to the reader to make sense of the sentence. It carves out a group of human beings who use this particular product of company A.

Evaluation: The use of positive appraisal items such as "perfect" (used twice), "savoury", "unsweetened" (although a marked lexical item used positively), "traditional", "consistent", "superior taste", "hygienically packed", "low in fat" and "calcium goodness" make it a positive evaluation and the make the readers believe in the story of the yoghurt manufactured by the company, to be the right choice for their family.

\section{Product 4(A)}

Ideology: In this context, the term "vital" has been used as a synonym to essential, which implicitly propagates the ideology that this product is mandatory for the consumers to buy. In the text, it is stated as, "will surely keep the clientele coming back for more.", apparently it claims that it creates authentic smoothies and cocktails that is why the clients will want it more and more but the text underpins the ideology of consumerism. It is exacerbating the insatiable desires of humans as Stibbe (2015) talked about such stories that run in the discourses, "Consumer can never be satisfied" (p. 38). In this advertisement, the insatiable wants and desires of the consumers are provoked. For the sake of consumerism, the purchase of unnecessary goods are promoted through the use of persuasive linguistic features; the use of the modal verb "will" and the adverb "surely" show high modality of the claim and represent it as a highly certain fact that the clients always want more of it.

The discourse also underlies the ideology that it is "the finest selection of fruit juices" which means that this juice is made of the finest selection of fruits, which is better than homemade juices.

Evaluation: There are positive appraisal linguistic items used for defining the characteristics of juice. An adjective with an explicit positive connotation, "finest", has been used in the opening of the text. Further, a cluster of linguistic items i.e. "vibrant addition" has been used in collocation, both the lexical items have positive connotations which amplify the positivity of description. Other positive appraisal items used, such as "colourful" and "authentic" make it a positive evaluation and make the reader think that this juice is the finest one.

\section{Advertisements Company B}

\section{Product 1(B)}

Ideology: The insatiable wants and desires of the consumers are provoked as stated in the text, "no matter which one you try...will always leave you craving for more." It is implicitly promoting the ideology consumerism and selling their products has been subtly employed. There is high modality reflected in the claim through the use of the modal verb "will" which makes it a fact that the consumers always want it more because of its unique taste.

Another ideology that is entailed implicitly in the discourse is that preserved food can be fresh, even if it is used after some time as in the text, the product "is packed in state of the art packaging which ensures its freshness and original taste." Although preserved food can be hazardous for human health but through the use of lexical items such as "freshness" and "original taste", it is implied that preserved food items have the same freshness in their texture, taste, and nourishment as that of fresh food. This discourse can be called destructive discourse as it is implicitly propagating the idea that preserved food is a substitute for fresh food; also promoting consumerism.

Framing: Purchase/ consumption of the product is mapped onto an enriched experience as stated, "Savor the wholesome goodness of our cheese for an enriched experience". The source frame of enriched experience is applied to the target domain of the taste of the product. The taste of the product is made equivalent to a pleasant or enriched experience which is a negative frame because it is promoting consumerism. An enriched experience has many alternative roots to be gained: it can be spending time with nature or family, eating some natural food if it is peculiarly about taste, or maybe of helping any living being in the ecosystem. Here, in the advertisement by company B, this particular feeling i.e. "enriched" can only be experienced through consumption of the product and that will fuel the basic agenda of the company i.e. of increase in consumerism.

Evaluation: The positive appraisal items such as "creamy", "natural", "uniquely delicious", "freshness", "original taste", "wholesome goodness" and "enriched experience" has been used to describe the product, which eventually has made the description a positive evaluation for the readers.

Identity: The discourse of product 1(B) has created two groups, in-group through the use of the pronoun "our" and outgroup through the use of the pronouns "you" and "your". The pronoun "our" is used twice for the manufacturers/producers of the product as "our" and pronouns "you" and "your" are used for the consumers/ readers. The readers are placed in the 
subject position. If they are already using the product or not but they are assumingly given the status of consumers of the product.

\section{Product 2(B)}

Identity: Two distinct groups are created i.e. in-group through the use of the pronoun "our", who are the owners of the company, and out-group is created through the use of the pronoun "you", who are consumers of the milk. The use of the pronoun in "purity helps you enjoy" puts the reader in the subject position as if they are already using the product and it is providing them with the unique taste of farm-fresh dairy.

Evaluation: The use of positive appraisal items such as, "traditional", "goodness", "impeccably fit" (which is used in collocation with each other), "freshness", "purity", "unique", "farm fresh", "hassle-free", "safe daily use" and "richness" has made it a positive evaluation that preserved pack of milk has the same fresh and unique taste, purity and traditional goodness as that of fresh milk that is obtained from the cows, kept in the village. For the sake of consumerism, the implicit expressions with positive connotations in the language system are used, to make the readers believe that the preserved milk can be equally pure and good as fresh milk. The word "safe" has been used with microwave, that the packaging is safe if kept in a microwave. Although the food heated in a microwave can be hazardous for human health, if used consistently but in this discourse, the use of appealing linguistic items with positive connotations has made the reader believe that microwave use is safe and hassle-free and retains the richness of the product.

\section{Product 3(B)}

Ideology: In the selected advertisement, the term "consumers" have been used, which reduces the users to the role of consumption only. It is covertly assigning an identity to human beings through language and promotes the ideology of consumerism, which is the purchase of their product.

Evaluation: The use of positive appraisal elements such as "colourful", "healthy wholesomeness", "unique blend", "personal favourite", "popular", "fun twist" and "exciting flavours" makes it a positive evaluation and make the readers believe that this milk is not only healthy but has exciting flavours that have made it popular for people among all ages.

\section{Product 4(B)}

Ideology: The story that the discourse of butter narrates is "Purchase of products leads to wellbeing" (Stibbe, 2015, p.26). The product is given an active role as stated "our butter spreads happiness" and a substitute to oil for cooking, written as, "a tasty alternative to oil to cook". The adjective "tasty" has been used with "alternative" to make it more persuading for the readers.

Evaluation: In the phrase, "tasty alternative to oil" the adjective "tasty" is used with "alternative", in which the unmarked word "tasty" is used as a positive appraisal pattern for their butter. It entails that oil is not tasty, using a negative appraisal pattern for it. Also, other positive appraisal items such as "uniquely crafted", "velvety in texture", "subtly salty", "perfect" and its equivalency to "happiness" through the use of metaphor make it a positive evaluation for the readers.

\section{Advertisements by Company "C"}

\section{Product 1(C)}

Ideology: In the text, the powder milk is presented as a substitute to fresh and natural milk stated as, "multi-purpose milk", "healthy source of Vitamin A, D and calcium", "provides energy" and "Goodness of this Fresh Milk Taste!" It implicitly propagates the story that this powder milk has energy, nutrients, and taste like fresh milk. For consumerism, the readers are attracted to these qualities through the use of language.

Evaluation: The use of positive appraisal items like "multi-purpose", "suitable", "healthy source", "energy", "Goodness" and "Fresh Milk" make it a positive evaluation and the readers believe in the story that the powder milk is an alternative to fresh milk.

\section{Product 2(C)}

Evaluation: The use of positive appraisal items such as "Pure", which is used in the name of the product and others like "multipurpose", "delicious", "ideal", "excellent natural source of Pure Vitamins, Minerals, Protein and Calcium", "Wholesome", "Nutritious", " $100 \%$ pure milk", "fresh" and "Pure Love" has made it a positive evaluation for the readers that this powder milk is pure, ideal and full of nutrients.

\section{Product 3(C)}

Ideology: Through the use of simile "as", the milk is made equivalent to fresh milk as stated that the milk "provides the same amount of Calcium and Vitamin D for the bones as whole milk". It is implicitly substituting fresh/natural milk with 
milk powder. Moreover, it gives an identity to its users that drinking this powder milk can give a fit lifestyle or drinking it is like living a fit life. It is also defining the social identity of its consumers and places them in the category of health-conscious people as stated, "Best choice for a fit lifestyle and health-conscious people".

Evaluation: The use of positive appraisal items such as "calcium-rich", "wholesome", "whole milk", "Best choice", "fit lifestyle", "health-conscious people", "fit", "High calcium" and "Rich Taste" have made the discourse of the powder milk, a positive evaluation. Certain words have positive or negative sense, even if they are removed from their current context. Such attitudinal terms are used in the discourse of the product, having a negative effect but in this context, they are used with such components and chemicals, which are considered harmful for health such as "Less than $0.1 \%$ fat", "no sugar", "no additives", "no flavour", "low cholesterol" and "Low fat". The use of these words, which convey positive meaning in the context also trigger making the discourse a positive evaluation and the reader would believe in the story of the product.

Identity: "Best choice for a fit lifestyle and health-conscious people" makes a category of individuals. It pre-supposes that the readers have a desire for a good lifestyle and the purchase of this product is the right choice for it. Moreover, it makes categorization of identity i.e. "health-conscious people", which denotes that those individuals who consume this product are health-conscious people; they are constructing an identity for its consumers through the purchase of the product. The use of the noun phrase has made it desirable for the readers and is considered as a goal. The reader assumes that if they purchase the product, they can make their lifestyle fit and they will be called health-conscious people.

\section{Product 4(C)}

Ideology: The very first line "The traditional taste of Dahi" implies that this dahi (yoghurt) has a different taste than all other dahi (yoghurt). The use of the pronoun "it" for yoghurt suggests that only it is enriched with minerals and vitamins. However, every form of yoghurt is naturally infused with minerals and vitamins.

Evaluation: The positive appraisal items like "traditional", "perfect", "naturally enriched", "essential", "growth", "development", "convenience" have made it a positive evaluation that only this yoghurt is enriched with vitamins and minerals that are necessary for growth and it is also perfect for eating in any form because of its traditional taste.

\section{Advertisements by Company "D"}

\section{Product 1(D)}

Ideology: It implicitly promotes the ideology that this drink is made of fresh and natural grapes through the use of a persuasive lexical item such as, "All Pure grape nectar", which persuades the reader that this drink is all pure and natural and can be a substitute to natural fruits. This ideology is implicitly promoting consumerism.

Framing: The target domain of the product brings the source frame of natural grapes to the mind of readers through the use of trigger words like "pure", "delicious taste of grapes", "All pure grape nectar". It implies that the product is made of natural grapes and this drink is a substitute for fresh grapes.

Identity: At the beginning of the text, the imperative sentence has been used, "start your day out right" in which the use of the pronoun "you" is reaching directly to the readers. It involves the readers and makes it a goal for the readers to achieve. The readers are compelled to start their day with this juice and called it the "right" choice. Through the persuasive linguistic features, consumerism is promoted which is replacing natural products.

Evaluation: The use of positive appraisal items such as "All Pure", "delicious", "grapes", "All pure grape nectar" has made it a positive evaluation for the readers that this drink is all made up of natural ingredients.

Salience: There is salience in the text because the basic level word, "grape" has been used from which the drink is made.

\section{Product 2(D)}

Ideology: In a single line statement, two ideologies are promoted. In the first part, it is implicitly stated that the juice of company " $D$ " has the same sweet taste as fresh mangoes, so it is a substitute for natural mangoes. In the second part, the high modal verb "must" has been nominalized, which gives the product an existence, which is important to consider as stated, "a must-have item for your family." It is promoting consumerism that this drink is necessary to buy or purchase.

Framing: The source frame of mangoes is applied to the target domain of the product, through the use of trigger words like "sweet taste of mangoes", "mango". It brings the fame of real mango to the mind as if this juice is also made of real mangoes, implicitly substituting natural fruit.

Evaluation: The use of positive appraisal items such as "sweet taste of mangoes", "mango" and "a must-have item" make it a positive evaluation and the readers believe in the story of the product. 


\section{Product 3(D)}

Ideology: "Pure perfection in a bottle" implies that this bottle of mango juice is made of pure mangoes which are preserved in a bottle by company "D". Like all other discourse, it also implicitly means that this drink is equivalent to natural mango because it is pure.

Evaluation: The use of positive appraisal items such as "pure perfection", "most loved drink", "right flavour and texture" and "enjoy" make it a positive evaluation that this drink is pure and is loved by everyone.

\section{Product 4(D)}

Identity: The use of the imperative sentence, "enjoy the tangy sweetness of pineapple Twist to take you on an adventure of taste" makes it a goal for the readers to achieve. Those consumers who will consume the drink will enjoy the flavour and will also take themselves on the adventure of taste. Here, the consumer is attributed as an "adventurer" who loves to dare and do daring tasks, which are thrilling and also have pleasure. The use of the pronoun "you" is putting the reader in the subject position by addressing them directly. It is implicitly promoting consumerism by assigning the identity of adventurers to its consumers.

Evaluation: Positive appraisal items such as, "tangy sweetness of pineapple", "adventure", "unique", "homely", "enjoy" and "loved" make it a positive evaluation for the readers, who would believe in the story that is drunk is equivalent to going on an adventure, also it is loved by everyone.

\section{Advertisements by Company "E"}

\section{Product 1(E)}

Framing: The source frame of mangoes is applied to the target domain of Mango Squash through the use of trigger words, "succulent mangoes", "natural vitamins" and "fun flavours". It brings the frame of natural mangoes to the mind of readers that this drink is made of natural mangoes, thus equivalent to natural mango.

Evaluation: Company E uses positive appraisal items for its product, implicitly with words that have associations with nature like "succulent mangoes", "natural vitamins", "energized" and "refreshed". These appraisal patterns present this product as equally good as natural mangoes. It can be called a destructive evaluation as it is replacing nature with artificial products.

\section{Product 2(E)}

Ideology: The description starts with "Made with real fruits", which implicitly states that it is a substitute for fresh fruits because this drink is also made of real fruits. Further, this idea is amplified that this drink is full of "goodness of mangoes, oranges, and lemons". For the sake of consumerism, the squash is made equivalent to fresh fruits.

Framing: Through the use of trigger words like "real fruits", "bursting", "goodness of mangoes, oranges, and lemons", the source domain of fresh fruits is applied to the squash to make it equivalent to fresh fruit and its goodness.

Evaluation: Positive appraisal patterns have been used for the product such as "real fruits", "goodness of mangoes, oranges, and lemons" and "refreshed". It is making it a positive evaluation that this product is made of real fruits and it has the same goodness as real fruits, in the form of squash.

\section{Product 3(E)}

Ideology: The ideology that runs through this advertisement is that this squash is made of natural oranges as stated, "Made from real oranges", which also implicitly makes the drink a substitute for fresh and natural oranges. The claim, "with the added benefits of Vitamin C to reinvigorate you." implies that the drink has more Vitamin C infused than real oranges.

Framing: There is a modification frame in the description because the trigger words "real oranges", "refreshingly citrusy flavour" with "added benefits of Vitamin C" brings a frame with little modification that this drink is better than real oranges because it has extra benefits of Vitamin C, to give energy.

Evaluation: Positive appraisal items such as "real oranges", "refreshingly citrusy flavour" "added benefits of Vitamin C" and "reinvigorate" have made it a positive evaluation for the readers that this drink is better than real oranges, thus promoting consumerism.

\section{Product 4(E)}

Ideology: The ideology that is embedded in the description of this product is that it is a better substitute for natural fruits because it is a blend of two natural products i.e. lemon and barley and company $\mathrm{E}$ has brought them in a single bottle as in 
the text, "a perfect concoction of sweet and sour" and "uses the natural taste of lemon and barley". Persuading vocabulary has been used to make the readers believe in this story, which underlies the story of an increase in consumerism.

Framing: The source frame of lemon and barley is applied to the target domain of squash through the use of trigger words, "sweet", "sour", "natural taste", "lemon", "barley" and "Vitamin C". It is propagating the idea that this squash is a good combination of two natural products and brought them together in a single bottle for their users.

Evaluation: Positive appraisal item such as "perfect concoction", "natural taste", "tantalize", "fulfilling" and "Vitamin C" is used to make it a positive evaluation for the readers that is a combination of two natural ingredients, which not only has good taste but also fulfill daily needs of Vitamin C.

Identity: The use of the pronoun "your", which is used twice, places the reader in the subject position and to reach out directly to the readers. The readers assume that they are already using this product.

To answer the first question based on analysis, which is to find the kind of stories developed by product manufacturers through their advertisements, it is found that the food manufacturing companies develop different forms of stories, as given

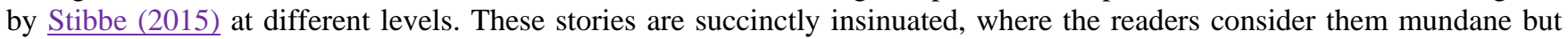
the advertisers ruminate and instill certain perceptions in readers' minds and the choices they make in purchase in daily life through the use of language. The stories that the display of the advertisement appear to be natural but they deploy specific frameworks, the way they want the audience to think and act. The advertisements of the selected companies can be called destructive discourses because, under the guise of consumerism, they are promoting environmentally destructive behaviour and do not go in concordance with ecosophy as defined by Stibbe (2015).

The type of stories, furthered by the advertisements of five selected companies, also direct the ecological preferences of the audience, through the use of language which is the second research question of the current study. The language in each advertisement is splurged succinctly. The story of consumerism is dominated through the use of ornate and lofty language. Language is used, not only to sell the product but also to set ecological preferences of the audience i.e. how to treat the environment. The stories mentioned in the analysis, propagated by the selected food manufacturing companies, use language in such a manner that makes their product a better substitute to natural products through the use of nominalization, transitivity, active and passive voice, simile, metaphor, modality, hyponymy, metonymy, entailment, and lexical choices. They inadvertently use such lexical items that are pertinent to natural products but in the advertisements, those attributes are associated with artificially produced products. The frames or linguistic schemas of natural products are exploited and applied to artificially processed food. The language in each advertisement, coupled with images, is curated with the diligence that also goes in concordance with the ideology of the company. The language used, is intimidating because they have purged nature and its resources completely; replaced nature with artificially manufactured food products. Their discourses manipulate language in such a manner to promote unsustainable consumerism and manipulating the insatiable desires of human beings, manoeuvering them to buy more and more. These stories, escalating ecologically destructive behaviour, have become so prevalent in the society that people have started believing in these stories and are accepted as reality. The artificially produced food products are replacing natural products despite their adverse effects on human health and the economy as well.

\section{CONCLUSION}

In the present study, an ecolinguistic analysis of the advertisements of five food manufacturing companies is carried out. Based on analysis, the study concludes that the food manufacturing companies use linguistic devices in such an emollient manner that the readers assume it to be for the sake of marketing of the product but that embeds certain stories. These stories are seemingly mundane but each story clad the ideology of consumerism with the help of language. Language plays a pivotal role in constructing stories and making the readers believe in those stories. The convictions that these stories instill in the human mind, do not only describe the product in a particular but also develop the perception of the audience; how to construe reality and the world. Agenda Setting Theory and Framing Theory also suggest that the advertisements peculiarly present an object. The media and advertisers, in particular, not only give salience to some objects and compel the audience to give more heed to but also the attributes of the selected object. The same has been observed in the advertisements for the five selected food manufacturing companies.

\section{LIMITATIONS AND FUTURE RESEARCH DIRECTIONS}

The research is made limited to the advertisements of five food manufacturing companies. These companies are selected based on the popularity of their products and the glamour that is added in their advertisements. The products of these selected companies are considered to be of quality and have a standard in taste. Furthermore, the study is made limited to the beverages and dairy products of the selected companies because these are the ones, which are used as a substitute for natural products. The beverages are considered as a substitute for fresh fruits and the processed dairy products are considered as a substitute for fresh milk and the products made from milk. 
Based on the limitations of the study, the first future direction reflects that the study may be conducted on a greater canvas involving a bigger number of advertisements, which may provide a better understanding of the nature of commercial stories set by the product manufacturers. Furthermore, apart from beverages and dairy products, the study may include other types of commercial advertisements to unfold the nature stories which become a cause of replacing the natural product with nature one.

\section{AUTHOR'S CONTRIBUTION}

Ms. Shah has collected the data and analyzed it. Dr. Ahmed guided her in writing the article. Dr. Ahmed and Dr. Nawaz also organized primary and secondary resources for literature review. Ahmed revised the article and finalized it.

\section{REFERENCES}

1. Ahmed, S.,\& Ashfaq, A.,. (2013). Impact of Advertising on Consumers' buying behavior through Persuasiveness, Brand Image, and Celebrity endorsement. Global Media Journal, 6(2), 149.

2. Ardèvol-Abreu, A. (2015). Framing theory in communication research. Origins, development and current situation in Spain. Revista Latina de Comunicación Social, (70). https://doi.org/10.4185/RLCS-1053en

3. Arowolo, O. (2017). Understanding framing theory. Lagos State University: Lagos, Nigeria.

4. Chan, R. Y. (2000). The effectiveness of environmental advertising: the role of claim type and the source country green image. International Journal of Advertising, 19(3), 349-375. https://doi.org/10.1080/026 $\underline{50487.2000 .11104806}$

5. Chen, S. (2016). Language and ecology: A content analysis of ecolinguistics as an emerging research field. Ampersand, 3, 108-116. https://doi.org/10.1016/j.amper.2016.06.002

6. Coleman, R., McCombs, M., Shaw, D., \& Weaver, D. (2009). Agenda setting. In K. Wahl-Jorgensen \& T. Hanitzsch (Eds.), The Handbook of Journalism Studies, 147- 160. New York: Routledge.

7. Davie, G. (2011). Framing Theory. Retrieved from https://masscommtheory.com/theory-overviews/framing-theory/

8. Haider, T., \& Shakib, S. (2018). A study on the influences of advertisement on consumer buying behavior. Business Studies Journal. )

9. Hamid, S. (2015). Influential Role of Language on People through Advertisements. East West University.

10. Hartmann, P., Apaolaza, V., \& Alija, P. (2013). Nature imagery in advertising: Attention restoration and memory effects. International Journal of Advertising, 32(2), 183-210. https://doi.org/10.2501/IJA-32-2-183-210

11. Jayakumar, A., \& Kiruthiga, A. (2019). Impact Of Green Advertising On Consumer Purchase Behaviour Towards Green Products (Astudy With Special Reference To Youngsters In Salem District). Nature, 476(7359), 214.

12. Johannessen, K. S., Meldere, I., Torvik, J. M., Aas, T. V., Krasnovs, A., Balteiro, B., . . Kraze, S. (2010). The language of advertising: Powerful, innovative and environmental? . New perspectives on sustainability, (2).

13. McCombs, M., \& Shaw, D. (2016). The Agenda-Setting. Agenda Setting: Readings on Media, Public Opinion, and Policymaking, 17. )

14. Mühlhäusler, P. (2019). Revisiting Greenspeak. In The Second Cognitive Revolution (pp. 81-88). Springer, Cham. https://doi.org/10.1007/978-3-030-26680-6_9

15. Naess, A., \& Drengson, A. R. (2008). Ecology of wisdom: writings by Arne Næss. Counterpoint Press.

16. Saeed, M., Ahmed, Z. U., \& Mukhtar, S.-M. (2001). International marketing ethics from an Islamic perspective: a value-maximization approach. Journal of Business Ethics, 32(2), 127-142. https://doi.org/10.1023/A:1010718817155

17. Stibbe, A. (2014). An ecolinguistic approach to critical discourse studies. Critical Discourse Studies, 11(1), 117128. https://doi.org/10.1080/17405904.2013.845789

18. Stibbe, A. (2015). Ecolinguistics Language, ecology and the stories we live. Routledge.

19. Yang, T., Lee, D. Y., Kwak, Y., Choi, J., Kim, C., \& Kim, S. P. (2015). Evaluation of TV commercials using neurophysiological responses. Journal of physiological anthropology, 34(1), 1-11. https://doi.org/10.1186/s40101015-0056-4

20. Yuniawan, T., Rokhman, F., Rustono, R., \& Mardikantoro, H. B. (2017). The study of critical eco-linguistic in green discourse. prospective eco-linguistic analysis. Humaniora, 29(3), 291-300.

https://doi.org/10.22146/jh.v29i3.27441 